CAPSULE COMMENTARIES

\title{
Capsule Commentary on Kesselheim et. al., Variations in Patients' Perceptions and Use of Generic Drugs: Results of a National Survey
}

\author{
Cameron M. Kaplan, PhD \\ Department of Preventive Medicine, University of Tennessee Health Science Center, Memphis, TN, USA.
}

J Gen Intern Med 31(6):647

DOI: $10.1007 /$ s11606-016-3670-x

(c) Society of General Internal Medicine 2016

$\mathrm{O}$ ver the past decade, there has been a drastic increase in the number of insurance benefit designs with high deductibles and tiered formularies, which has made brand-name drugs more expensive for consumers. ${ }^{1}$ At the same time, the "patent cliff" of the early 2010s led to an increase in choice of generic medications. Not surprisingly, utilization of generic drugs has increased as a percentage of all drugs dispensed. ${ }^{2}$ However, what remained unclear was how consumer perceptions of generic drugs had evolved over time, given patients' increasing exposure to them.

This study by Kesselheim et al. $^{3}$ presents findings from a survey on consumer preferences and beliefs about generic and brand-name drugs. Previous studies, in particular a study by Shrank et al. based on data from $2007,{ }^{4}$ found that patients were skeptical of generic drugs, and the results of this study show that this has changed. For example, the 2007 study found that $30 \%$ of respondents believed that "branded drugs are more effective than generics", while this newer study found that only $13 \%$ had similar views. However, on other measures, little progress has been made. For example, the 2007 study found that $38 \%$ of patients preferred generic drugs, while the current study found that only $27 \%$ of patients preferred generics. As the authors note, the wording and order of the questions and the survey population are slightly different between studies, which makes comparison somewhat difficult. Ideally, the same survey should be repeated over time in order to truly study changes in preferences.

One concerning finding is that generic drug skepticism was much higher in non-white patients, which suggests that minorities may be missing out on some of the benefits of cheaper medications. This may a consequence of the widely studied racial disparities in general distrust of the healthcare system, ${ }^{5}$ and could be a contributor to disparities in cost-related non-adherence. This warrants further study to understand why minority patients are more skeptical, and how to increase trust and utilization of generic medications among this population.

Corresponding Author: Cameron M. Kaplan, PhD; Department of Preventive MedicineUniversity of Tennessee Health Science Center, Memphis, TN, USA (e-mail: ckaplan@uthsc.edu).

\section{Compliance with Ethical Standards:}

Conflict of Interest: The author has no conflicts of interest with this article.

\section{REFERENCES}

1. Claxton G, Rae M, Panchal N, et al. Health benefits in 2015: stable trends in the employer market. Health Aff. 2015. doi:10.1377/hlthaff.2015.0885.

2. Hartman M, Martin AB, Lassman D, Catlin A, Team NHEA. National health spending in 2013: growth slows, remains in step with the overall economy. Health Aff. 2015;34(1):150-160.

3. Kesselheim AS, Gagne JJ, Franklin JM, et al. Variations in patients' perceptions and use of generic drugs: results of a national survey. J Gen Intern Med. 2016. doi:10.1007/s11606-016-3612-7.

4. Shrank WH, Cox ER, Fischer MA, Mehta J, Choudhry NK. Patients' perceptions of generic medications. Health Aff. 2009;28(2):546-556.

5. Armstrong K, McMurphy S, Dean LT, et al. Differences in the patterns of health care system distrust between blacks and whites. J Gen Intern Med. 2008;23(6):827-833. 